\title{
Oral Manifestations and Dental Management of Patients with Chronic Renal Failure on Hemodialysis
}

\author{
Nazish Ashfaq Khan ${ }^{1}$ \\ Shairose Aziz ${ }^{2}$ \\ Maria Kwiatowski ${ }^{3}$ \\ Farrukh Anwar Mirza ${ }^{4}$ \\ Reza Haider ${ }^{4}$ \\ Bilal Jamil $^{5}$ \\ BDS, MFDSRCS, FFDRCSI \\ BDS, MSc \\ BDS \\ BDS \\ BDS \\ MBBS, FCPS
}

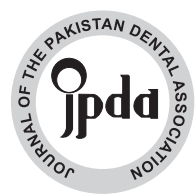

\begin{abstract}
AIM:The incidence of Chronic renal failure (CRF) is increasing all over the world. Most of these patients will show oral signs or symptoms either related to the renal disease or its treatment.

The treatment may require dietary and fluid restrictions but despite this most of the patients progress to end stage renal failure (ESRF) and require further treatment of haemodialysis, peritoneal dialysis or renal transplantation. This research aims to present the dental manifestations a patient undergoing hemodialysis may present with and also make recommendations for the general dentist to improve their patient's oral hygiene status.

METHODOLOGY:Our inclusion criteria included patients suffering from chronic renal failure of either gender with age 18 years and above, non smokers and requiring hemodialysis for at least every month. Whereas,patients with unstable medical conditions requiring hospitalization other than dialysis in the past 30 days, or with co morbidities such as stroke.

RESULTS:A comprehensive outline of the different manifestations in the patients undergoing hemodialysis; caries, periodontal disease, halitosis, lichen planus like lesions and xerostomia is discussed in this article along with the number of patients who seroconverted to Hepatitis B and C during the course of their treatment.

CONCLUSION: Patients with Chronic renal failure presenting with significant medical histories and associated drug regimens, which may considerably affect the oral environment.

KEY WORDS: Chronic renal failure, dialysis, oral manifestations, GDP recommendations.

HOW TO CITE: Khan NA, Aziz S, Kwiatowsk M, Mirza FA, Haider R, Jamil B. Oral Manifestations and Dental Management of Patients with Chronic Renal Failure on Hemodialysis. J Pak Dent Assoc 2017;26(4):158-63.

DOI: https://doi.org/10.25301/JPDA.264.158

Received: 29 October, 2017, Accepted: 05 December, 2017
\end{abstract}

\section{INTRODUCTION}

hronic renal failure (CRF) is a disease which leads to a progressive loss of renal function. It is characterized by five stages in an ascending order of severity with the last stage being end stage renal disease (ERSD).

A number of aetiologies have been identified in its occurrence: the most common being diabetes mellitus, hypertension and glomerulonephritis. Renal failure can also result from an over dosage of drugs metabolized by the kidney. ${ }^{1}$

1. Specialist OSOM. Dept. of Oral and Maxillofacial Surgery(OSOM). James Cook University Hospital Middlesbrough UK.

2. STEP Teacher ITREB Dept. of Education. Ismail Tariqah and Religious Education Board.

3. SHO Dept. Of Oral Medicine. Kings College London.

4. National Dental Examining Board of Canada.

5. Medical Director. Tabba Institute of Renal Diseases, Karachi.

Corresponding author: "Dr. Nazish Ashfaq Khan"<aansa19@yahoo.com >
People with chronic renal failure are usually treated with two main therapies: Hemodialysis and Renal transplantation. Although these therapies save patients' lives, they also pose serious systemic complications.

Patients on hemodialysis experience excessive bleeding due to the administration of anticoagulants, hypertension, uremia, anemia, increase risk of infections and decrease platelet count. Patients undergoing renal transplantation suffer from the effects of immunosuppressive drugs.

Mortality rate amongst patients afflicted with chronic renal failure may increase in presence of such multiple complications that can prove to be life threatening. ${ }^{2}$ Hence the risks of chronic renal failure treatment most of the times outweighs its benefits.

Aforementioned metabolic and hematologic systemic manifestations of chronic renal failure also leads to several changes within the oral cavity: Calculus, high levels of urea in saliva, ammonia-like odour, xerostomia, bleeding from 
oral mucosa, stomatitis, paleness of gingivae, drug-induced gingival hyperplasia, loss of lamina dura, radiolucent lesions within the maxilla and mandible, abnormal remodelling of bone post extraction, hypoplasia of enamel delayed tooth eruption, decreased caries prevalence, dental erosion, tenderness to tooth percussion, mobility and malocclusion of teeth. ${ }^{3,4,5}$

Data on epidemiology of CRF are available for many European countries but it is limited for developing countries. ${ }^{6}$ In the subcontinent, chronic renal failure is amongst the most common systemic diseases. The incidence of end-stage renal disease in Pakistan is estimated to be about 100patients/million population. ${ }^{7}$ Oral soft and hard tissues are significantly affected as a result of CRF. ${ }^{5}$ In renal failure, oral manifestations correlate with markers of malnutrition and inflammation. ${ }^{8}$ Renal patient's dental problems can compromise their general health and hinder medical management. ${ }^{2}$

The goal of dental treatment in patients with renal disease must be the early and frequent evaluation of the oral cavity for the source of infection. ${ }^{2}$ Thus, the role of dental professionals becomes eminent in diagnosing the alterations within the oral cavity of CRF patients, thereby taking appropriate measures to reduce further complications. Unfortunately in Pakistan, not many studies have been done to project the oral presentations of CRF patients. Also, many times due to lack of researches these manifestations go unnoticed by the oral health care professionals. Hence, it is important for oral health care professionals to be familiar with these manifestations.

In view of CRF expansion with in the country at an alarming rate and the need of the knowledge that dentists must have, we aim to present a research study highlighting the oral manifestations of chronic renal disease, in patients undergoing hemodialysis.

In addition, we are also making recommendations the general dentist should undertake to improve the oral hygiene status of patients afflicted with CRF.

\section{METHODOLOGY}

A retrospective study was done of 191 patients over a three-month period at the Tabba Institute of Renal Diseases, Karachi where patients undergoing hemodialysis were examined.

The study was conducted at the Tabba Institute of Renal Diseases from July 2009-Oct 2009. Our inclusion criteria included patients suffering from chronic renal failure of gender with age 18 years and above, non smokers and requiring hemodialysis for at least every month. Whereas, patients with unstable Medical conditions requiring hospitalization other than dialysis in the past 30 days, or with co Morbidities such as stroke, TIA, GI disorders leading to malabsorption were excluded.

Non-invasive oral examination was carried out for these patients after receiving verbal consent from them. Three calibrated examiners examined all patients. Patient's oral cavities were examined under standard conditions of good light and vision using a mouth mirror, a pen torch and dental probe.

\section{RESULTS}

200 patients had been registered at the Tabba Institute of Renal Diseases. Out of these 191 were examined for the study. The majority of patients in our study consisted of females. (Table 1) A percentage wise breakdown of the oral manifestations seen is listed in table no 2. A significant number of comorbidities existed in the patients, HPT being the most common. (Table no 3) A large number of patients underwent dialysis between 1-5 years and only a small percentage had been undergoing dialysis for more than 10 years. (Table no 4) Prior to dialysis $59 \%$ of patients had Hep C and only 14\% had Hep B. A more detailed personal history about lifestyle was not taken from the patients to prevent uneasiness. (Table no 5) $30 \%$ of Non-Hepatitis patients developed Hep B and $15 \%$ developed Hep C as a result of their dialysis. (Table no 6) The majority of patients tried to adhere to twice daily brushing. $6 \%$ used other

Table 1- Gender Distribution

\begin{tabular}{|l|r|}
\hline Male & $47 \%$ \\
\hline Female & $53 \%$ \\
\hline
\end{tabular}

Table 2- Oral Manifestations

\begin{tabular}{|l|r|}
\hline Plaque/Tartar & $83 \%$ \\
\hline Periodontitis & $73 \%$ \\
\hline Dental Caries & $55 \%$ \\
\hline Halitosis & $43 \%$ \\
\hline Xerostomia & $22 \%$ \\
\hline Lichen Planus & $6 \%$ \\
\hline
\end{tabular}

Table 3- Co-morbidities

\begin{tabular}{|l|r|}
\hline Hypertension & $67 \%$ \\
\hline Diabetes & $24 \%$ \\
\hline IHD & $7 \%$ \\
\hline Arthritis & $2 \%$ \\
\hline Gastric Ulcer & $2 \%$ \\
\hline Asthma & $1 \%$ \\
\hline
\end{tabular}

Table 4- No. of years of undergoing hemodialysis

\begin{tabular}{|l|r|}
\hline $1-5$ years & $12 \%$ \\
\hline $6-10$ years & $7 \%$ \\
\hline $11-15$ years & $3 \%$ \\
\hline
\end{tabular}


Table 5- Pre-Dialysis Status

\begin{tabular}{|l|c|}
\hline Hepatitis B & $14 \%$ \\
\hline Hepatitis C & $59 \%$ \\
\hline
\end{tabular}

Table 6- Hepatitis Developed During and After Dialysis

\begin{tabular}{|l|r|}
\hline Hepatitis B & $30 \%$ \\
\hline Hepatitis C & $15 \%$ \\
\hline
\end{tabular}

Table 7- Brushing Habits

\begin{tabular}{|l|r|}
\hline Twice a day & $45 \%$ \\
\hline Once a day & $39 \%$ \\
\hline Nil & $8 \%$ \\
\hline Other Methods & $6 \%$ \\
\hline
\end{tabular}

Table 8- Concurrent Drug Therapy

\begin{tabular}{|l|r|}
\hline Calcium Supplements & $24 \%$ \\
\hline Anti Hypertensives & $20 \%$ \\
\hline Insulin & $8 \%$ \\
\hline Anti Anxiety & $5 \%$ \\
\hline Gout & $5 \%$ \\
\hline Diuretics & $5 \%$ \\
\hline Ant Acid & $5 \%$ \\
\hline Aspirin & $6 \%$ \\
\hline Ca Channel Blockers & $4 \%$ \\
\hline Vit D & $1 \%$ \\
\hline Erythropoietin & $1 \%$ \\
\hline Digoxin & $1 \%$ \\
\hline
\end{tabular}

methods like miswak. (Table no 7)

\section{DISCUSSION}

The incidence of chronic renal failure (CRF) is on the rise, the world over. ${ }^{9,10}$ It has been defined as a progressive failure of renal function associated with a reduced glomerular filtration rate (GFR). This is measured clinically by creatinine clearance rate (CC). More common causes include diabetes, hypertension, glomerulonephritis and autoimmune diseases. ${ }^{11,12}$

CRF can be present for years before symptoms are noted. Clinical signs and symptoms include nocturia, polyuria, cloudy urine or blood in the urine. Patients with renal disease may develop a number of other conditions including hypertension, weight loss, anaemia and osteodystrophy ${ }^{13}$ and be on multiple drug regimens, which will further affect the oral environment.

De Rossi and Glick reported that $90 \%$ of patients with declining renal function showed oral signs and symptoms either related to the renal disease or its treatment. ${ }^{13}$

Treatment of renal failure leads to many clinical manifestations in the oral cavity. Lichenoid like disease can arise due to antihypertensive medications. ${ }^{12}$

Other signs in the oral cavity include: Calculus, high levels of urea in saliva, ammonia-like odour, xerostomia, bleeding from oral mucosa, stomatitis, paleness of gingivae, drug-induced gingival hyperplasia, loss of lamina dura, radiolucent lesions within the maxilla and mandible, abnormal remodelling of bone post extraction, hypoplasia of enamel delayed tooth eruption, decreased caries prevalence, dental erosion, tenderness to tooth percussion, mobility and malocclusion of teeth. ${ }^{15,16,17}$

\section{Halitosis}

Diminished renal function results in an increase increased levels of urea in the blood and saliva, leading to the production of ammonia. Because of this reason, these individuals have a characteristic halitosis (uremic fetor), which occurs in onethird of patients on hemodialysis. ${ }^{18}$

Apart from urea, other factors include an increase in the concentration of phosphates and proteins and changes occurring in the $\mathrm{pH}$ of saliva. ${ }^{14,12,19}$ In our study $43 \%$ of patients complained of Halitosis.

\section{Periodontitis}

Gavaldá et al..$^{20}$ examined the oral mucosa of 105 patients with chronic renal failure and noted mucosal lesions, uremic stomatitis and candidal infections occurring in $37 \%$ of patients. Klassen and $\mathrm{Krasko}^{21}$ examined 45 patients undergoing hemodialysis and reported that $100 \%$ of them presented with some degree of periodontal disease, $64 \%$ showed severe gingivitis and $28 \%$ presented with early periodontitis regardless of the duration of dialysis. In another study, examining 44 patients undergoing hemodialysis, Wilson and Kornman reported, periodontal disease (i.e., severe gingivitis and ulcers) was present in all cases. $^{22}$

In our study, $73 \%$ of patients had periodontitis, $83 \%$ had varying levels of plaque and tartar buildup and only 1 $\%$ had gingival bleeding.

In an American study of 45 hemodialysis patients, all had some form of periodontal disease and oral debris, $64 \%$ had severe gingivitis and a higher-than-normal score for the decayed, missing and filled index, and $28 \%$ had early periodontitis regardless of the duration of dialysis. ${ }^{23}$

\section{Gingival Hyperplasia}

Dental plaque acts as a predisposing factor for nifedipineinduced gingival enlargement ${ }^{24}$, but is not imperative to its development. ${ }^{25}$ Neither the dosage, nor the duration of treatment is related to the prevalence of gingival enlargement. ${ }^{26} \mathrm{~A}$ few studies have reported a decrease in gingival enlargement by switching to alternative drugs, such as calcium channel blockers ${ }^{27,28}$, however, some gingival enlargement may still occur with these drugs. ${ }^{29}$ 
$3 \%$ of the patients in our study presented with gingival hyperplasia. There is no concrete evidence to suggest whether this was due to the use of calcium channel blockers.

\section{Xerostomia}

The treatment of CRF may require restriction of fluid intake due to the decreased ability of the kidneys for excretion. Dryness of the oral mucosa can thus be attributed to a number of factors: Fluid intake restriction and multiple drug therapies Xerostomia is related to the overall volume status of patients who are discouraged from drinking excess fluid. Possibly contributing to the dryness is the use of mouthwashes containing alcohol. Dysgeusia and uremic fetor, bad taste and odour are caused not only by xerostomia but also by the presence of urease-splitting oral organisms, which metabolize urea (present in high levels in these patients) and thus elaborate ammonia.enlargement may still occur with these drugs. ${ }^{30} 22 \%$ of our patients presented with xerostomia.

Long-term xerostomia can lead to caries and gingivitis, resulting in difficulties with speech, retention of dentures, problems with mastication, mucositis, dysphagia, and loss of taste. ${ }^{31}$

\section{Caries}

There hasn't been any conclusive evidence to suggest an increase in dental caries in patients with CRD. ${ }^{12}$ The increased $\mathrm{pH}$ of saliva (resulting from urea hydrolization) has led to an antibacterial effect suggesting a protective mechanism against caries. ${ }^{32}$

Despite that, $55 \%$ of our patients presented with caries. Due to the lack of radiographic examination during this study, the extent of caries could not be established.

\section{Lichen Planus}

Lichenoid disease can arise, as a result of associated drug therapy (e.g., diuretics, beta-blockers). ${ }^{32,33,34,35,36}$ Similarly, oral hairy leukoplakia has seen to occur as a result of drug-related immunosuppression. . $^{37,38,39} 6 \%$ of the patients in our study presented with reticular and atrophic lichen planus.

Most patients with CRD progress to renal failure with renal dialysis or kidney transplant being the mainstay of treatment.

Haemodialysis filters the patient's blood in a machine outside the body, usually performed around 3 times per week. Haemodialysis carries increased risk of contracting $\mathrm{HIV}, \mathrm{HBV}$ or $\mathrm{HCV}^{40}$

About $30 \%$ of patients, examined, reported to have developed Hepatitis B during the course of their dialysis and $15 \%$ reported to have progressed from Hep B to Hep C.

\section{Dental Management and Recommendations}

The importance of the maintenance of good oral hygiene cannot be stressed enough.

Our results showed $45 \%$ no of patients brushed their teeth twice a day. $39 \%$ brushed them once a day. $8 \%$ did not brush them at all and $6 \%$ used other methods of oral hygiene. In light of the oral manifestations highlighted in our study, we have made the following recommendations regarding the dental management of patients with CRD and hemodialysis.

\section{RECOMMENDATIONS}

1- The dentist should check the patient's medical history and medication on each visit.

2- Patients undergoing dialysis should have regular dental visits, and special attention should be paid to prophylaxis and fluoride application.

3- Request a coagulation screen prior to carrying out surgical procedures and use local haemostatic measures to control bleeding postoperatively.

4- Dental treatment should be carried on non-dialysis days to prevent risk of bleeding due to heparin.

5- Universal cross infection measures should be adopted to prevent patients from contracting blood borne viruses. 6- Antibiotic dosage and analgesics may have to be altered due to the altered renal function.

7- The decision to stop /alter anti-coagulant therapy should be taken only after consultation with the physician in charge.

8- The use of salivary substitutes should be encouraged.

9- Non-alcoholic mouthwashes should be recommended to prevent dryness of the oral mucosa.

10 - Never use the arm with the AV fistula for administration of IV drugs or blood pressure measurement.

\section{CONCLUSION}

Patients of chronic renal failure were found to suffer from multiple oral conditions. Most common of these were the lichenoid reactions, xerostomia, halitosis, periodontitis and dental caries. Their medical status may be responsible for an increased risk of oral manifestations.

\section{CONFLICT OF INTEREST}

None declared

\section{REFERENCES}

1. Colledge NR, Walker BR, Ralston SH. Davidson's principles and practice of medicine. 21st ed. United Kingdom: 
Elsevier Company; 2010.

2. Rossi SS D, Glick M. Dental considerations for the patient with renal disease receiving hemodialysis. J Am Dent Assoc. 1996;127: 211-219.

3. Bottomley WK, Cioffi RF, Martin AJ. Dental management of the patient treated by renal transplantation: preoperative and postoperative considerations. J Am Dent Assoc. 1972;85: 1330-1335.

4. Naylor GD, Fredericks MR. Pharmacologic considerations in the dental management of the patient with disorders of the renal system. Dent Clin North Amer. 1996;40: 665-683. 5. Heard E Jr, Staples AF, Czerwinski A W. The dental patients with renal disease. Precautions and guidelines. J Am Dent Assoc. 1978;96: 792-796.

6. Bokhari SAH, Khan AA. Growing burden of noncommunicable diseases: The contributory role of oral disease, Eastern Mediterranean region perspective. Eastern Mediterranean Health Journal. 2009;15: 1015-1016. 7. Naqvi SAJ. Nephrology services in Pakistan. Nephrol Dial Pakistan. 2000;15: 769-771.

8. Chen LP et al. Does periodontitis reflect inflammation and malnutrition status in hemodialysis patients? Am J Kidney Dis. 2006;47: 815-22.

9. Ansell, D., \& Feest, T. UK renal registry report. Bristol: UK renal registry. 2002.

10. McDonald, S. P., \& Russ, G. R. ANZDATA registry report. Adelaide, South Australia: Australia and New Zealand dialysis and transplant registry. 2002.

11. Klassen, J. T., \& Krasko, B. M. The dental health status of dialysis patients. J Can Dent Assoc. 2002;68: 34-38. 12. Proctor, R., Kumar, N., Moles, D., Stein, A., \& Porter, $\mathrm{S}$. Oral and dental aspects of chronic renal failure. J Dent Res. 2005;84: 199-208.

13. Thorman, R., Neovius, M., \& Hylander, B. Clinical findings in oral health during progression of chronic kidney disease to end-stage renal disease in a Swedish population. Karolinska Institute. Scand J Urol Nephrol. 2009;43:154-9.

14. Rossi, S. S., \& Glick, M. Dental considerations for the patient with renal disease receiving haemodialysis. J Am Dent Assoc. 1996;127: 211-9.

15. Bottomley WK, Cioffi RF, Martin AJ. Dental management of the patient treated by renal transplantation: preoperative and postoperative considerations. J Am Dent Assoc. 1972;85:1330-35.

16. Naylor GD, Fredericks MR. Pharmacologic considerations in the dental management of the patient with disorders of the renal system. Dent Clin North Amer. 1996;40:665-683. 17. Heard E Jr, Staples AF, Czerwinski AW. The dental patients with renal disease. Precautions and guidelines. J Am Dent Assoc. 1978;96:792-796.
18. Dental considerations for the patient with renal disease Silvia Martí Álamo 1, Carmen Gavaldá Esteve 1, Ma Gracia Sarrión Pérez 1 J Clin Exp Dent. 2011;3:e112-9. 19. 8. de la Rosa García E, Mondragón Padilla A, Aranda Romo S, Busta- mante Ramírez MA. Oral mucosa symptoms, signs and lesions, in end stage renal disease and non-end stage renal disease diabetic patients. Med Oral Patol Oral Cir Bucal. 2006;11:467-73.

20. Gavaldá C, Bagán JV, Scully C, Silvestre FJ, Milián MA, Jiménez. Renal hemodialysis patients: oral, salivary, dental and periodontal findings in 105 adult cases. Oral Dis. 1999;5:299-302.

21. 2. Klassen JT, Krasko BM. The dental health status of dialysis patients. J Can Dent Assoc. 2002;68:34-38. 22. Wilson TG, Kornman KS. Fundamentals of periodontics. 2nd ed. Chicago: Quintessence Publishing Co.; 2003. 23. Naugle K, Darby ML, Bauman DB, Lineberger LT, Powers R. The oral health status of individuals on renal dialysis. Ann Periodontol. 1998; 3:197-205.

24. Nishikawa S, Tada H, Namasaki A, Kasahara S, Kido J, Nagata T, et al. Nifedipine-induced gingival hyperplasia: a clinical and in vitro study. J Periodontol. 1991;62:30-35. 25. Morisaki I, Kato K, Loyola-Rodriguez JP, Nagata T, Ishida $\mathrm{H}$. Nifedipine-induced gingival overgrowth in the presence of gingival inflammation in rats. J Periodontal. Res 1993;28:396-403.

26. Barclay S, Thomason JM, Idle JR, Seymour RA. The incidence and severity of nifedipine-induced gingival overgrowth. 1992;J Clin Periodontol. 19:311-314. 27. Lederman D, Lumernan H, Reuben S, Freedman PD. Gingival hyperplasia associated with nifedipine therapy. Oral Surg Oral Med Oral Pathol. 1984;57:620-622. 28. Cebeci I, Kantarci A, Firatli E, Carin M, Tuncer O. The effect of verapamil on the prevalence and severity of ciclosporin-induced gingival overgrowth in renal allograft recipients. J Periodontol. 1996;67:1201-1205. 29. Westbrook P, Bednarczyc EM, Carlson M, Sheehan H, Bissada NF. Regression of nifedipine-induced gingival hyperplasia following switch to a same class calcium channel blocker, isradipine. J Periodontol. 1997;68:645-650. 30. Klassen JT, Krasko BM. The dental health status of dialysis patients. J Can Dent Assoc. 2002;68:34-38. 31. Porter SR, Hegarty A, Scully C. An update of the etiology and management of xerostomia. Oral Surg Oral Med Oral Pathol Oral Radiol Endod. 2004;97:28-46.

32. Davidovich E, Davidovits M, Eidelman E, Schwarz Z, Bimstein E. Pathophysiology, therapy, and oral implications of renal failure in chil- dren and adolescents: an update. Pediatr Dent. 2005;27:98-106.

33. Chau NY, Reade PC, Rich AM, Hay KD. Allopurinolamplified lichenoid reactions of the oral mucosa. Oral Surg 
Oral Med Oral Pathol. 1984;38:397-400.

34. Hogan DJ, Murphy F, Burgess WR, Epstein JD, Lane PR. Lichenoid stomatitis associated with lithium carbonate. J Am Acad Dermatol. 1985;13:243-246.

35. Markitziu A, Katz J, Pisanty S. Lichenoid lesions of oral mucosa associated with ketoconazole. Mykosen 1986;29:317322.

36. Torrelo A, Soria C, Rocamora A, Moreno R, Ledo A . Lichen planuslike eruption with esophageal involvement as a result of cyanamide. J Am Acad Dermatol. 1990;23:11681190.

37. Greenspan JS, Greenspan D. Oral hairy leukoplakia: diagnosis and management. Oral Surg Oral Med Oral Pathol.
1989;67:396-403.

38. King GN, Fullinfaw R, Higgings TJ, Walker RG, Francis DM, Wiesenfeld D. Gingival hyperplasia in renal allograft recipients receiving ciclosporin $\mathrm{A}$ and calcium antagonists. J Clin Periodontol. 1993;20:286-293.

39. GN, Healy CM, Glover MT, Kwan JT, Williams DM, Leigh IM, et al. Prevalence and risk factors associated with leukoplakia, hairy leukoplakia, erythematous candidosis, and gingival hyperplasia in renal transplant recipients. Oral Surg Oral Med Oral Pathol. 1994;78:718-726. 40. Pol, S. Hepatitis C virus infection in hemodialyzed patients and kidney allograft recipients. Adv Nephrol Necker Hosp. 1995;24:315-30. 